\title{
Transplantation: Unbelievable Evolution and an Amazing Gift to Human Population
}

\section{Pramoda Earla*}

Department of Microbiology, Aditya Degree College [PG Courses], Andhra University, Andhra Pradesh, India

*Corresponding author: Pramoda Earla, Department of Microbiology, Aditya Degree College [PG Courses], Affiliated to Andhra University, Kakinada, East Godavari, Andhra Pradesh, India, Tel: +91-7416948660; E-mail: pramodaearla@gmail.com

Rec date: June 10, 2014, Acc date: June 13, 2014, Pub date: June 16, 2014

Copyright: (c) 2014 Earla P. This is an open-access article distributed under the terms of the Creative Commons Attribution License, which permits unrestricted use, distribution, and reproduction in any medium, provided the original author and source are credited.

\begin{abstract}
There are many people who lost their valuable lives due to organ loss or improper functioning of particular organ, which leads to the death of that particular person. Transplantation can be defined as the transfer of any essential organ, cell, or tissue from one location to another with in a same individual or from one person to another for the purpose of replacing the patient's damaged organs. There are different types of transplantations depending up on the type of transplant, which includes, Heart, kidney, liver, lung, pancreas, intestine, and thymus, bones, cornea, skin, heart valves, nerves and veins. Although there are several drawbacks involved, transplantation has become an unbelievable evolution by developing day by day and becoming available to the common people to save their valuable lives, thus it can be regarded as an amazing gift to the human population.
\end{abstract}

Keywords: Allograft transplantation; Autograft transplantation; Organ transplantation; Tissue transplantation; Kidney transplantation; Heart transplantation; Liver transplantation; Lung transplantation; Pancreatic transplantation; Hair transplantation

\section{Introduction}

We have seen many people till now who lost their valuable lives due to organ loss or improper functioning of particular organ, which leads to the death of that particular person. These people may not be acquainted with the word Transplantation, as there is no such evolution in in ancient days, and no chance to save their valuable lives by transferring organs from one person to another. Transplantation can be defined as the transfer of any essential organ, cell, or tissue from one place to another with in a same individual or from one person to another for the purpose of replacing the patient's damaged or absent organs.

Transplantation has become a clinical practice and a strategy for overcoming many diseases which will not be readily curable by any existing therapies [1]. We can differentiate transplantation mainly into two types. Those are allograft transplantation and autograft transplantation. Autograft transplantation is a transplantation which is performed within the same person by transferring organs or tissues from one place to another within the same body, whereas allograft transplantation is a transplantation which is performed between two different individuals or between two species.

There are different types of transplantations depending up on the type of transplant. Heart, kidney, liver, lung, pancreas, intestine, and thymus will come under organ transplantation and bones, cornea, skin, heart valves, nerves and veins will come under tissue transplantation. The most commonly transplanted organs are kidneys which are followed by liver and heart.

\section{Kidney Transplantation}

Kidney transplantation is the treatment of choice for last stage kidney disease [2]. It is a process of transferring new kidneys by replacing previously effected or diseased kidneys [3]. Most common renal abnormality is the Ureteral duplication, where two ureters drain a single kidney [4]. There are many kidney donation programs conducting worldwide and the success of paired kidney donation programs depends on the number of patients involved [5]. The success of kidney transplantation technology has become $95 \%$ in one year [6]. Kidney transplantation have become as an effective treatment and serving as a pillar of renal replacement therapy [7].

\section{Heart Transplantation}

The heart is the first organ formed from the cells of the Inner Cell Mass (ICM) or epiblast of the blastocyst in early embryogenesis. Mature contracting cardiac muscle cells, called cardiomyocytes, are terminally differentiated and unable to regenerate in the adult heart $[8,9]$. No drug of molecular entity has ever been approved by FDA as a new treatment for heart disease and failure for humans in the last few decades [9]. All donors were in sinus rhythm and the average heart rate was 8124 beats per minute (bpm). Heart failure constitutes the end-stage of many cardiopathies and is characterized by a ventricular dysfunction [10].

Treatment of heart failure is mostly risk related. But, heart transplantation is the only curative therapy available [11]. The first heart transplant performed in 1967 by using a heart from a DCD donor by Dr. Christiaan Barnard. The donor was a 25 -year old female who had been involved in a road traffic accident. Her heart had stopped and Dr. Barnard and his team resuscitated the organ by placing her onto cardiopulmonary bypass (CPB). Four decades later we have employed a similar strategy to resuscitate the heart of a DCD donor 23 minutes after asystole [12]. Due to considerable ethical concerns associated with in-vivo cardiac resuscitation, the introduction of a reliable means for recovering the organ outside of 
Page 2 of 3

the donor's body may be of critical importance in establishing the DCD donor as a routine source of organs for heart transplantation [13].

Solid organ transplantation (SOT) is an extremely viable and mostly unavoidable treatment modality for patients with end-stage organ diseases, and outcomes of SOT have improved a lot over the past few decades. Since the first successful human heart transplant performed in 1967, Heart transplants have become the third most common organ transplant operation in many transplant centers [14].

\section{Liver Transplantation}

Liver transplantation is probably one of the most challenging surgical procedures a surgeon can face. [15]. Liver transplantation is a well-accepted therapeutic option for patients with end-stage liver diseases [16]. Alcohol is one of the major causes for liver disease [17]. Liver Transplantation for Hepatocellular Carcinoma in patients with cirrhosis is identified as the best therapeutic approach [18]. Hepatocellular carcinoma is a common solid tumor. The only curative treatment options for hepatocellular carcinoma are liver resection and liver transplantation in now a day [19]. Bleeding esophageal varices in cirrhosis have been considered an indication for liver transplantation by some respected liver transplantation programs [20].

Liver transplantation has become a common procedure at many major medical centers, [21] as improvements in surgical technique and transfusion strategies have reduced blood loss associated with liver transplantation [22].

However, recipients undergoing liver transplantation require varying amounts of blood products due to the haemostatic changes related to severity of the end stage hepatic dysfunction, collateral circulation and portal hypertension. The procedure still carries a risk of excessive blood loss that is associated with a high risk of mortality and morbidity [23]. Blood loss during liver surgery is a most complex issue affected not only by the clotting reserve but also by operative methods and presence of other factors like portal hypertension which may play a vital role in the bleeding tendency of the patients [24].

Although liver transplantation is an amazing gift to human population, it should be considered for patients with progressive liver disease only when no other options are available [25].

\section{Lung Transplantation}

Lung transplantation is the therapeutic option for patients with severe pulmonary disease who are refractory to medical therapy [26]. The most common form of interstitial lung disease of unknown origin is idiopathic pulmonary fibrosis [27]. Lung transplantation has become one of the treatments of choice for patients with advanced idiopathic pulmonary fibrosis [28]. Lung transplant has been the preferable treatment for above 40 years for several end-stage respiratory diseases. The first human lung transplant was performed in a patient with bronchogenic carcinoma who died because of renal failure after 18 days of lung transplantation in 1963 [29].

\section{Pancreatic Transplantation}

Pancreas transplant is preferable for patients with Type 1 as well as Type 2 diabetes [30]. Pancreas transplantation achieved insulin independence in the 1960s and 1970s [31]. As of December 2010, above 35,000 pancreas transplants were observed by the International
Pancreas Transplant Registry and nearly 9,000 by the Collaborative Transplant Study databases. Pancreatic transplantation in diabetic patients is divided into 3 major categories, those performed simultaneously with a kidney transplant, usually from a deceased donor, those performed after a successful kidney transplant in which the kidney taken from either a living or deceased donor and pancreas transplantation alone in the complete absence of a kidney transplant [32].

\section{Hair Transplantation}

Hair transplantation has become popular as a method of treating hair loss in recent years. Reports of successful hair transplants observed from 1930s in Japanese literature. The large grafts that are used throughout the 1960s and 1970s are eventually replaced by minigrafts in the 1980s and mini-micrografting in the early 1990s. Follicular Unit Transplantation method first introduced to the medical literature in 1995. Subsequently, in 2002, Follicular Unit Extraction method was explained by Bernstein and Rassman. Follicular Unit Extraction method is the process that nearly $1 \mathrm{~mm}$ diameter micrografts taken from the donor area are placed into predrilled holes in the recipient region. This technique has provided a less invasive method for graft production, without the forming a linear scar and it results in low pain and discomfort at the donor site [33].

Large grafts were used early in the history of hair transplantation. It will be possible to create a natural-looking, undetectable transplant using large grafts but very few were done. It required careful planning which includes spacing of the first session and a minimum of four sessions followed up with one or two touch-up sessions after the hair had grown. In some cases, grafts in the first session were placed too far apart, which results in "dolls head" look. Later these grafts will become progressively smaller and were called minigrafts and micrografts. The final endpoint was follicular unit grafts, which are the natural groups of hair growing in the scalp and consist of 2 to 4 hairs [34].

\section{Conclusion}

This technology of transplantation has improved a lot and has involved seriously in saving many lives. Although there are several drawbacks involved, transplantation has become an unbelievable evolution by emerging day by day and became available to the common people to save their valuable lives, by providing some assurance and it can be regarded as an amazing gift to the human population.

\section{References}

1. Karaoz E (2013) The Role of Mesenchymal Stem Cells in Organ Transplantation Immunomodulatory and Anti-inflammatory Properties of Mesenchymal Stem Cells for Application in Organ Transplantation. J Transplant Technol Res 4: e128.

2. Mas VR, Maluf DG (2013) Biomarker Discovery and Validation in Kidney Transplantation. J Mol Biomark Diagn 4: e115.

3. Martinez BS, Gasanova I, Adesanya AO (2013) Anesthesia for Kidney Transplantation-A Review. J Anesth Clin Res 4: 270.

4. Bozkurt B, Tokaç M, Dumlu EG, Yarar O, Kiliç M (2014) Modified Extravesical Ureteroneocystostomy in Cadaveric Kidney Transplantation with Completely Duplicated Ureters: A Case Report. J Transplant Technol Res 4: 131.

5. Salvadori M, Bertoni E (2013) Acute Antibody-Mediated Rejection in Kidney Transplantation: Clinical and Therapeutic Aspects. J Nephrol Ther 4: 146. 
Citation: Earla P (2014) Transplantation: Unbelievable Evolution and an Amazing Gift to Human Population. J Transplant Technol Res 4:

Page 3 of 3

6. Sousa MG, Linhares MM, Salzedas A, Gonzalez AM, Rangel E, et al. (2014) Death Receptor in the First Year after Simultaneous Pancreas/ Kidney Transplantation. J Nephrol Ther 4: 150.

7. Bragazzi NL, Nicolini C (2014) Nanogenomics for Personalized Nanomedicine: An Application to Kidney Transplantation . Cell Mol Biol 60: 115.

8. Parsons JF, Smotrich DB, Gonzalez R, Snyder EY, Moore DA, et al. (2011) Defining Conditions for Sustaining Epiblast Pluripotence Enables Direct Induction of Clinically-Suitable Human Myocardial Grafts from Biologics-Free Human Embryonic Stem Cells. J Clin Exp Cardiolog S9: 001.

9. Parsons XH (2013) Cellular Medicine for the Heart-the Pharmacologic Utility and Capacity of Human Cardiac Stem Cells. J Clin Exp Cardiolog S11: e001.

10. Batlle M, Roig E, Pulgarin MJ, Campos B, Ramírez J, et al. (2013) Molecular Changes of the Angiotensin Converting Enzyme 2 Pathway in Myocardial Tissue from Heart Failure Patients Undergoing Heart Transplantation. J Clin Exp Cardiolog S9: 004.

11. Richter M, Polyakova V, Gajawada P, Pöling J, Warnecke H, et al. (2012) Oncostatin M Induces FGF23 Expression in Cardiomyocytes. J Clin Exp Cardiolog S9: 003.

12. Ali AA, Freed D, Large S (2013) The Donation after Circulatory Death Donor can be a Source of Organs for Cardiac Transplantation. J Clin Exp Cardiolog S9: 007.

13. Ali AA, White C, Freed D, Ali Z, Large S (2013) Ethicality of Heart Transplantation from Donation after Circulatory Death Donors. J Clin Exp Cardiolog S9: 006.

14. Chiu B, Sergi C (2013) Malignancy after Heart Transplantation: A Systematic Review of the Incidence and Risk Factors Compared with Other Solid Organ Transplants. J Clin Exp Cardiolog S9: 005.

15. Baccarani U, Rossi M (2011) Liver Transplantation Surgery: How We Do It Today In Italy. J Anesthe Clinic Res 4: 306.

16. Salem EH, Taha M, Aziz A, Alsebaey A, El-Ella KA, et al. (2014) Recurrent Hepatitis C Virus (Genotype 4) Infection after Living Donor Liver Transplantation: Risk Factors and Outcome. J Liver 3: 148.

17. Vassallo G, Mirijello A, Antonelli M, Ferrulli A, Addolorato G (2013) Liver Transplantation for Alcoholic Liver Disease. J Alcoholism Drug Depend 2: 143.

18. Vitale A, Salinas F, Zanus G, Lombardi G, Senzolo M, et al. (2013) Could Sorafenib Disclose New Prospects as Bridging Therapy to Liver Transplantation in Patients with Hepatocellular Carcinoma? J Liver 2: 134.

19. Cho W, Kim JM, Choi JY, Lee SH, Moon HH, et al. (2013) Combination Therapy of Sirolimus and Sorafenibfor Recurrent Hepatocellular Carcinoma after Liver Transplantation. Chemotherapy 2: 118.
20. Orloff MJ (2013) Liver Transplantation during Fifty-Three Years' Experience with Randomized Controlled Trials of Emergency Portacaval Shunt for Bleeding Esophageal Varices in Cirrhosis. Surgery Curr Res 3: 140.

21. Yoo MC, West JM, Eason JD,Vanatta JM (2012) The Advantages and Disadvantages of Perioperative Transesophageal Echocardiography during Liver Transplantation. J Anesthe Clinic Res 4: 331.

22. Whiteley JR, Hand WR, Plunkett HL, Taylor JM, Stoll WD, et al. (2013) Epsilon-Aminocaproic Acid in Liver Transplantation: A Three-Year, Retrospective Review. J Anesthe Clinic Res 4: 328.

23. Khalil M, Fayed N, Abdullah M, Refaat E, Suliman H, et al. (2013) Preoperative Low Dose Recombinant Activated Factor VII Effect during Liver Transplantation. J Anesthe Clinic Res 4: 319.

24. Fayed N, Hegazy O, Tanaka K (2012) Bloodless Liver Transplantation: ROTEM guided Rational Prophylactic use of Recombinant Activated Factor VII. J Anesth Clin Res 3: 240.

25. Mukherjee S (2012) Boceprevir and Calcineurin Inhibitors - is there a Role for Treating Hepatitis C Recurrence after Liver Transplantation? J Antivir Antiretrovir 4: xv-xvi.

26. Afshar K (2012) Time to Lung Transplantation: Lung Allocation Score and Other Factors. J Pulmonar Respirat Med 2: e110.

27. Di Scioscio V, Cecchelli C, Greco L, Guerrieri A, Morelli A, et al. (2013) Re-activation of IPF and Appearance of Cancer on the Native Lung after Single Lung Transplantation. OMICS J Radiology 2: 125.

28. Ameer F, Crawford GB (2013) Barriers to the Provision of Optimal Palliative Care in a Patient Awaiting Lung Transplantation. J Pulm Respir Med 3: 151.

29. Al-Githmi I (2013) Early Experience with Lung Transplantation in Patients with Idiopathic Pulmonary Fibrosis. Surgery Curr Res 3: 128.

30. Aniskevich S, Perry DK (2013) Anesthesia for Pancreas Transplantation. Pancreatic Dis Ther 3: 122.

31. Chaib E, Macedo RA, Santos VR, D’Albuquerque LAC (2013) Pancreas Transplantation-Surgical Technique. Pancreatic Dis Ther 3: 120.

32. Farooq U, Al-Shraideh Y, Rogers J, Farney AC, Orlando G, et al. (2013) Technical Aspects of Pancreas Transplantation with Portal Venous Drainage. Pancreatic Dis Ther 3: 115.

33. Kutlubay Z, Kucuktas M, Engin B (2013) Hair Transplantation in the Cicatricial Alopecias. Hair Ther Transplant 3: 109.

34. Straub PM (2012) Harvesting Grafts for Hair Transplantation. Hair Ther Transplant 2: e103. 